\title{
O ENSAIO EM DiÁlogo. DA TERRA FIRME AO ARQUIPÉLAGO RELACIONAL ${ }^{1}$
}

\section{Liliana Weinberg}

A linha de trabalho que estou desenvolvendo na atualidade propõe uma leitura densa do ensaio, na medida em que este corresponde a uma forma textual em chave de diálogo que reproduz formas de sociabilidade intelectual e que, em razão de sua capacidade para a intermediação entre discursos e práticas, formações e instituições, contribui para consolidar e, inclusive, para postular - um espaço de encontro para a confluência de linhas de pensamento e redes de intercâmbio de ideias. ${ }^{2}$

Para me referir à noção de uma "leitura densa" do ensaio, partirei de uma proposição aparentemente modesta: "todo dizer é um querer dizer". Sem cair nas velhas tentações da intencionalidade, considero,

\footnotetext{
${ }^{1}$ A versão original deste texto foi publicada em espanhol em R. Dhondt e D. Vandesboch (eds.), Transnacionalidad e hibridez en el ensayo hispánico. Un género sin orillas, Leiden/ Boston, Brill/Rodopi, 2017. Agradecemos à autora e aos editores do livro a autorização para a tradução e publicação do texto, o qual foi mantido basicamente em seu formato original. ${ }^{2}$ Esta é a proposta que anima o projeto coletivo sob minha responsabilidade, "El ensayo en diálogo. Ensayo, prosa de ideas, campo literario y discurso social. Hacia una lectura densa del ensayo", que conta com o apoio do Conacyt, México. Uma leitura densa do ensaio, inspirada na abordagem de thick reading - que, por sua vez, vincula-se com a noção de descrição densa do comportamento ou thick description, de Gilbert Ryle, retomada por Clifford Geertz (1988) -, é aquela que não só explica um comportamento em si mesmo, mas também revisa seu contexto, já que só dessa maneira aquele pode ser significativo para um observador externo. Algo semelhante ocorreu com a nova história intelectual que, precisamente em razão de sua atenção particular ao contexto, conseguiu se afastar da tradicional história das ideias.
} 
para dizê-lo com as palavras de Tomás Segovia (1990), que no caso dos textos "todo dizer é um querer dizer", isto é, o mundo do sentido não é um âmbito de neutralidade, antes, trata-se de um mundo valorado. Assim, a respeito da intencionalidade, deve-se deslindar - como o faz Jean-Marie Schaeffer (2013) - o que o autor quer dizer e o que o próprio texto quer dizer. Todo ensaio entra em diálogo com um horizonte epocal de sentido e com uma organização valorativa do mundo que, por sua vez, incorpora e reinterpreta. Como já expressaram Lukács e Benjamin de maneira insuperável - os quais recolhem os ensinamentos de Simmel a respeito da tensão entre espírito subjetivo e espírito objetivo -, ambos preocupados com a relação entre o texto e a vida, é possível falar, com o primeiro autor, da relação entre o juízo e o próprio processo de julgar, ou ainda, com o segundo, de uma relação entre o poético e o poetizado.

"Os textos querem nos dizer algo, ou algo disseram que não podemos perder, ou estão prestes a nos dizer algo", sustenta Borges em La muralla y los libros. E o ensaio é um colocar em prática ativo desse querer dizer, desse diálogo do sujeito com seus semelhantes, seu tempo e sua cultura, porque, mais uma vez com Segovia (1990, pp. 514), “um fenômeno é captado sempre como uma unidade e como um sentido, e não como uma agregação de elementos ou qualidades cujo 'resultado' é o fenômeno". Por outro lado, "o sujeito é pura relação com o mundo" (p. 518) e, portanto, há uma maneira de reagir diante da realidade e de dar a essa realidade um tratamento conseguinte. Esse querer dizer, essa afirmação da radical relacionalidade que nidifica em toda a obra, permite que o texto exerça uma forma de intervenção no discurso social, e medeie e articule distintas noções, debates, ideias-força. Esse querer dizer outorga ao ensaio uma orientação necessária que diz respeito a sua configuração como desdobramento de sentido.

Apelarei a outra expressão, fortemente paradoxal, de Segovia, para mostrar que "o conteúdo de um texto está fora dele". O ensaio traz ao presente, representa, recria as condições de diálogo e resposta com um determinado estado de coisas. É fundamental para o ensaio a necessidade de recuperar, restaurar - ou inclusive deflagrar - as condições de diálogo inteligente e inaugurar novos circuitos de conversação que dotem as palavras de sentido. Dessa forma, para entender o ensaio devemos efetuar duas operações de uma vez: tanto atender à leitura do próprio texto, como à sua inscrição. O ensaio representa simbolicamente as condições de diálogo e encontro em uma comunidade imaginada que o próprio 
texto contribui para representar, postular, recriar, conjecturar, restaurar, simbolizar.

Desse modo, longe de podermos pensar em um ponto primeiro de origem, em um gesto unilateral pelo qual um sujeito se decide a ver seu objeto e comunicar seus descobrimentos, trata-se - evocando as propostas de Bakhtin - de um encontro dialógico, responsivo e responsável pela palavra. Isso nos aproxima de uma questão maior: a intencionalidade de todo ato de sentido. A respeito disso, em um trabalho sobre a obra de Octavio Paz, sustento que um de seus grandes aportes éticos e estéticos foi, precisamente, essa permanente dotação de sentido ao mundo. Com efeito, a atitude de quem ensaia é a atitude de quem põe valor, de quem tenta dar sentido ao mundo e a seu próprio dizer em relação com ele.

O ensaio toma a palavra em um mundo banhado pela linguagem. Desse modo, cada vez que procurei descrever um texto fui levada a reconhecer que seu dizer inscreve-se em uma densa rede de discursos que ele, por sua vez, reconfigura. O ensaio, prosa mediadora entre a prosa, ingressa em um espaço de diálogo e encontro, isto é, em um espaço onde se dá uma relação entre valor e sentido, cujas condições ele mesmo re-presenta, re-pensa, re-interpreta, re-configura. Porém, ao mesmo tempo, como discurso em segundo grau (CHIAMPI apud GONZÁLEZ ECHEVARRÍA, 2001, pp. 8o-81), sua forma de mediação está dada e autorizada pela especificidade de sua própria forma.

É assim que, sem deixar de reconhecer a possibilidade de estudar a configuração de sentido do próprio texto, sua autonomia relativa e sua organização - o texto ensaístico manifesta densidade sintática e semântica, regras de estruturação e representação artística, recorrência de certas estratégias discursivas, traços formais e estilísticos -, tampouco podemos deixar de afirmar que é possível descobrir nele constelações de sentido que o habitam e o atravessam, assim como estruturas elementares de sociabilidade e estruturas de sentimento que se encontram, ao mesmo tempo, dentro e fora dele, que preexistem a seu exercício de intelecção e, simultaneamente, são reinterpretadas por ele. O ensaio é, por um lado - como marca Nelson Goodman para toda a obra artística -, exemplo de si mesmo e de seu dizer; mas o ensaio também é exemplo de seu próprio fazer, performance de um ato de intelecção responsável, geradora de novos significados.

Sem deixar de reconhecer que há no ensaio um reenvio permanente à presença do autor como garantia de sentido, não podemos cair em uma intencionalidade inocente. Também é necessário considerar a inserção 
específica do fazer ensaístico nas tradições artísticas e de pensamento, convenções literárias e posicionamentos estéticos, redes e horizontes discursivos, assim como seu enlace com estilos de pensar e processos de simbolização com os quais entra em diálogo implícito. Marc Angenot (1982), em La parole pamphlétaire, mostrou como é necessário, para caracterizar o ensaio, torná-lo um dos membros dessa organização dinâmica e em plena ebulição, que é a da prosa não ficcional.

Alguns dos elementos básicos que trabalhei em meus próprios estudos do ensaio são, em primeiro lugar, colocar em evidência uma intencionalidade do texto, o qual só é compreensível se o colocamos na trama de práticas de intercâmbio simbólico de ideias, estruturas de sentimento e sociabilidade, formas discursivas, horizontes ético-jurídicos com os quais entra em diálogo. Dessa forma, procuro evitar ler o texto de maneira atomizada ou reduzi-lo às intenções do autor, e insisto na necessidade de atender às redes e "estruturas elementares de sociabilidade", um termo adotado por autores como Jean-François Sirinelli, Michel Winock ou François Dosse. Enquanto o primeiro afirma que estudar as representações intelectuais conduz a traçar uma espécie de "eletroencefalograma das grandes correntes ideológicas que percorreram uma sociedade", assim como a fazer um "eletrocardiograma das grandes palpitações de uma comunidade", o último se pergunta como se dá o fenômeno da transmissão de ideias, de vetores de pensamento, de sistemas mais ou menos conformados, em direção à sociedade (DOSSE, 2006). E se tudo isso já é suficientemente complexo para pensar os processos que se dão na França, quanto mais complexa será a relação entre o eletroencefalograma intelectual e o eletrocardiograma social em países como os nossos, onde a produção intelectual dos grupos cuja postura confronta modelos de legitimação próprios do primeiro mundo entram em uma atormentada relação, que poucas vezes se manifesta como acordo ou representatividade plena e muitas vezes como desacordo, tensão, heterogeneidade, dilaceramento, cisão, a respeito da sociedade?

Por outro lado, segundo alguns autores, também é necessário atender ao "engaste" ou inscrição do texto em diferentes contextos discursivos, já que, como diz Roberto González Echevarría (2001, pp. 68-69), "o ensaio, como prática literária, não tem engaste genérico próprio” e, portanto, tem que declará-lo, assumi-lo e encená-lo como parte de seu próprio "processo de enunciação", de modo que averiguar a que tipo de discurso adere o ensaio é "fundamental para sua cabal compreensão". 
Outro tema que considero fundamental para o estudo do gênero é a relação entre questões literárias e jurídicas, que nos conduz a problemas de representação, representatividade, legitimidade. A respeito disso, interessa-me a possibilidade de transladar ao campo latino-americano o tipo de abordagem que está realizando Gisèle Sapiro (1999; 2011) para o caso dos escritores franceses. Em particular, temas como os de responsabilidade, boa fé e compromisso com a verdade próprios do escritor devem ser examinados como construção histórica e como reinterpretação de questões jurídicas que se dão no seio do campo intelectual e que, por sua vez, estão ligadas, por exemplo, a problemas como a liberdade de expressão, a liberdade de imprensa, os direitos de autor, os circuitos de circulação de ideias, o jogo das empresas editoriais e as instituições políticas e culturais.

Por fim, em um esforço para descobrir algo que chamei "caixa preta" do ensaio, isto é, uma matriz de sentido que nos dê a chave de leitura do texto e de sua própria interpretação do contexto, recupero essa categoria fundamental que é o "cronotopo" bakhtiniano, que permitiu nos conscientizarmos de que no texto se encontram centros organizadores de sentido que garantem uma conexão de relações temporais e espaciais assimiladas artisticamente na literatura. Recordemos que, para esse grande crítico, o cronotopo determina a unidade artística da obra literária em suas relações com a realidade e inclui sempre "um momento valorativo" (BAJTIN, 1989). Permito-me enfatizar que a noção de cronotopo permite estender uma ponte não só entre o mundo e o texto, como também entre o mundo representado e o próprio processo de representação, intelecção, interpretação, característicos do ensaio. Como genialmente mostrou Theodor W. Adorno, o ensaio representa não apenas o mundo interpretado, mas o próprio processo de interpretação desse mundo. Penso que se faz justiça ao legado de Bakhtin ao lembrar que, se o próprio termo nos remete ao tempo-espaço, o cronotopo inclui um inescapável aspecto social, valorativo. Considero que o ensaio nos envia a um espaçotempo social de encontro entre o público e o íntimo; porém, se ele representa o encontro, ao mesmo tempo o instaura, o postula e o assimila simbolicamente a figuras como as do livro e o diálogo entre amigos.

É necessário, portanto, atender à relação da constelação significativa do texto e suas regras de estruturação com o mundo do autor e do leitor; com o âmbito social e cultural em que ambos estão imersos (formas de sociabilidade intelectual e artística, recuperáveis por meio da leitura 
de cartas, da evocação de encontros, debates, conferências, integração de associações e sociedades literárias etc.); com os fenômenos ligados às "comunidades discursivas" (MAINGUENEAU, 2001), "sociedades de discurso" e "estruturas de sentimento" (WILLIAMS, 1980) correspondentes a distintas épocas, assim como às formações e instituições próprias do campo literário (editoras, arquivos, bibliotecas, revistas), e inclusive artístico (problemas próprios da representação e o diálogo entre as artes), que podem ser colocadas em relação com questões maiores de representação e estilo.

Esse vínculo do ensaio com certas condições de produção concretas e práticas de sociabilidade intelectual, às quais denominei o para cá do ensaio, mostra-nos a relação do fazer do ensaísta com os aspectos materiais e sociais da escrita, além de sua inscrição em um marco de discursividade social e sua inserção em redes de debate que atravessam os distintos campos (intelectual, artístico etc.), assim como as distintas esferas do acontecer social e cultural com as quais o ensaio dialoga. Porém, não devemos incorrer no risco de reduzir a leitura do ensaio às condicionantes materiais e sociais de produção, já que existe, ademais, um para lá do ensaio que diz respeito às condições de compreensão e interpretação dos textos: trata-se da relação do ensaio com o horizonte de inteligibilidade de sua época, com certa visão de mundo, com o nomeável, o pensável, o escrevível, próprios de cada etapa intelectual, com o sistema de valores e normas que o ensaio reinterpreta, à medida que se inscreve em um horizonte epistêmico, ético e estético.

Essas instâncias próprias do para cá e do para lá do ensaio articulam-se e colocam-se em relação por meio da configuração ativa do texto. Isso também se pode dizer da complexa figura do autor, para cuja compreensão considero muito valiosas as observações de Edward Said (1983) a respeito da passagem da filiação à afiliação que todo autor traduz e elabora em função de seu próprio texto. A respeito disso, em anos recentes também se tornou evidente um forte giro subjetivo e escritural do ensaio, com a incorporação criativa e o cruzamento de fronteiras entre o discurso autobiográfico, a representação da experiência, a exploração da memória, a construção da figura do autor nos limites entre ficção e não ficção...

Longe, então, de considerar as operações do ensaísta como estratégias ligeiras, e longe de submeter a interpretação do ensaio a um processo de leitura rarefeita, proponho contemplá-las em toda a sua complexidade e densidade, em toda a força de seu querer dizer, já que são uma infinidade 
de níveis aqueles com os quais o ensaio entra em diálogo, e isso só pode ser buscado por meio de uma interpretação densa. Proponho ver também as operações ensaísticas ligadas à comunicação intersubjetiva, ao papel de mediação que adota o escritor e ao estabelecimento de vínculos sociais sobre a base de um encontro intelectual e existencial com seu leitor e sua época. O próprio ingresso de leituras e citações se dá no ensaio sob a forma da incorporação das vozes dos outros e o compromisso vital com as ideias, o diálogo, o debate.

Em síntese: para uma compreensão do ensaio, sua leitura deve orientar-se tanto para o que Delcroix e Hallyn (1995) chamam a "descrição" do texto como para aquilo que denominam sua "inscrição", isto é, deve atender tanto à própria configuração textual, a seu dizer, a seu caráter de exemplo de si mesmo, como a seu querer dizer, à sua inscrição no horizonte social do discurso, de modo que é preciso atender não só à organização da trama textual, como também aos diversos âmbitos e séries em que se inscreve seu dizer e que, por sua vez, representam-se no próprio ensaio, dando lugar a um exercício de responsabilidade, de resposta e de representatividade da palavra.

Por fim, desejo acrescentar um último componente, que diz respeito à relação estreita e de dupla implicação daquilo que, em termos de Castoriadis (2013), podemos chamar o instituidor e o instituído. Desse modo, inclusive para que possamos nos referir a este recorte que se denominou "ensaio latino-americano", sua própria caracterização como tal implica a assunção de uma série de traços compartilhados que se apoiam, por sua vez, em outro conceito que atua como instituidor e instituído ao mesmo tempo: o conceito de cultura. Dito conceito foi abordado e atua em dois níveis simultaneamente, como continente e como conteúdo, como aval de um discurso que, ao mesmo tempo, o avaliza, em permanente dupla implicação. Nos últimos anos assistimos à crise desse conceito, sobretudo no que tange a uma interpretação substancial do gênero, em favor de uma intensa problematização de seus supostos, assim como à emergência de um novo arquipélago de enfoques relacionais.

Na sequência, procurarei analisar alguns exemplos disso, a partir da passagem entre distintos momentos-chave dessa relação entre ensaio e cultura, relação que denominei, inspirada em uma das coleções do Fondo de Cultura Económica (FCE), "o ensaio em terra firme” e, em um percurso inverso à viagem de descoberta da América, o trânsito que denominei, a 
partir de uma expressão de Juan José Saer (1991), “o gênero sem margens”, para desembocar, nessa viagem do centro às margens, do continente às ilhas, em um "arquipélago relacional", conjunto sempre instável e em permanente reconfiguração, que deslocou a visão totalizadora da cultura latino-americana para novas formas e novas dinâmicas.

\section{O ENSAIO EM TERRA FIRME}

Com essa imagem designei o momento de normalização do ensaio como forma do fazer intelectual na América Latina, vinculado à assinatura de um novo contrato de intelecção entre as noções de literatura, cultura e leitura, que acompanhou um rico momento de fundação de instituições também consideradas culturais. O conceito de cultura se converteu em um conceito-chave, que se movia em dois níveis ao mesmo tempo. Segundo Raymond Williams (1980), o conceito de "cultura" pode ser entendido tanto com referência a um modo de vida particular como à expressão desse modo de vida, e inclusive ao modo de reconstituí-lo. Os antecedentes modernistas desse processo podem ser rastreados já em Ariel, de Rodó, em 1900, no qual, mais uma vez evocando González Echevarría, deu-se uma complexa operação de retorno ao modelo do diálogo platônico como subtexto ao qual apela o professor, quem toma a palavra e, ao mesmo tempo, toma a voz em seu nome. Esse primeiro modelo, que teve uma admirável expansão na América Hispânica, encontrará um interessante primeiro momento de reinterpretação em "La utopía de América" de Pedro Henríquez Ureña e na recepção dessa obra por parte de José Carlos Mariátegui: um encontro no ano-chave de 1928, em que o autor dos Siete ensayos resenha a obra do autor dos Seis ensayos. José Carlos Mariátegui foi um dos intelectuais que viu com maior claridade o papel que o livro e a biblioteca desempenhavam nesse momento, como se comprova em Temas de nuestra América (1928), que mostra o possível vínculo entre cultura e literatura. O processo alcança visibilidade com a obra de Alfonso Reyes, sua própria definição de ensaio e a articulação do gênero com um projeto editorial (aquele do FCE) e com um momento de expansão das grandes revistas culturais, como Cuadernos Americanos e Sur; um momento culminante, por volta dos anos 1940, com a aparição de livros como De la conquista a la independencia de Mariano Picón-Salas (1944) e El ensayo americano de Medardo Vitier (1945). 
O ensaio ofereceu, então, uma solução simbólica para a necessidade dos intelectuais de fundar um lugar de articulação entre pensamento e ação. Ao falar do ensaio em terra firme, fiz referência a um momento singular do ensaio e da intelectualidade latino-americana, quando não só se normaliza o gênero, mas também se normaliza uma forma de articulação do intelectual com a sociedade e as instituições do Estado por meio do livro, da revista e da indústria editorial. Nesse caso, é fundamental o lugar que ocupa o conceito de cultura, a noção de inteligência, o modelo da conversação culta e a figura do professor: a voz do professor. Esse conceito avaliza o fazer interpretativo da inteligência hispano-americana e é avalizado por ela.

Como diz Roberto González Echevarría (2001, p. 15), "através do ensaio a questão da identidade cultural, ou seja, a formulação de um conceito de cultura que sustente a ideia de uma literatura latino-americana reúne a política e o pensamento social e político em geral”. Por outro lado, dizer que o ensaio alcançou sua terra firme significa que nesse momento se estabelece uma ética do próprio campo intelectual, diferente de outras esferas, como mostrou Gisèle Sapiro (1999; 2011) para o caso francês nesses mesmos anos, quando os homens de letras desenvolveram uma ética profissional diferente da responsabilidade penal, ao reclamar para si valores propriamente intelectuais, que eles universalizaram, como a verdade e a beleza.

A noção de responsabilidade se converte em elemento-chave para a legitimação do gênero e a prática de sociabilidade com a qual ele se articula e que, simultaneamente, o sustenta e se sustenta nele. $\mathrm{O}$ cronotopo do encontro intelectual e o exercício de responsabilidade da inteligência é, aqui, fundamental. Sustento que esse momento coincidiu, no para cá do ensaio, com a "janela de oportunidade" de certa abertura de entendimento entre a inteligência e o Estado, que coincidiu com a possibilidade de ampliar o espaço de interesse público e contribuiu para reforçar algumas condições culturais, tais como, por exemplo, a possibilidade de expansão da indústria do livro e a passagem do centro de gravidade da língua da Espanha para a América, com o crescimento dos níveis de alfabetização, a expansão das classes médias e o fortalecimento de instituições como a escola e a biblioteca. Trata-se de um momento riquíssimo, que coincide com a Segunda Guerra e o primeiro pós-guerra, antes do avanço do congelamento de posições, próprio da Guerra Fria, no qual se redefine a relação entre o ensaio, a ética e o jurídico, de modo que a "autonomia 
literária” é repensada também a partir da ideia de responsabilidade individual e coletiva. $\mathrm{O}$ ensaísta assume a responsabilidade e a boa fé no exercício da verdade como uma forma de "compromisso do escritor como intelectual que defende uma causa universal". Assim, havia um modelo de ensaio por trás dos ensaios concretos, como havia um modelo interpretativo que se nutria permanentemente do conceito de cultura, o qual permitia também oferecer uma narrativa integradora de cultura por trás das reflexões sobre o tema.

A "cultura" se converte em termo-chave, evocado até hoje, submetido à crítica até hoje. Em "Paradojas de la cultura”, publicado no suplemento "El Ángel” do jornal mexicano Reforma, o ensaísta Gabriel Zaid (2013, p. 2) observa:

Em meados do século XX, o gabinete presidencial tinha uma escolaridade média que chegava somente ao bacharelado. Entretanto (o que é o subdesenvolvimento!), muitos funcionários da época acreditavam nos livros, na arte, na cultura, como algo importantíssimo para a vida pessoal e nacional. Alguns foram grandes escritores. Agora há funcionários em posições hierárquicas altas com doutorados no estrangeiro, aos quais não é fácil explicar que a cultura sim nos importa.

Apesar de termos passado, na América Latina, não "do descontentamento à promessa”, como queria Henríquez Ureña (1928), mas da esperança ao desencanto, aceito as bondades da etapa em que se defendia um conceito integrador de cultura, embora também não queira idealizá-la, pois, na realidade, ela teve suas linhas de tensão, seus avanços e suas contradições. Por um lado, permitiu fortalecer e ampliar a participação de crescentes setores da população no espaço público, em razão de uma estratégia de multiplicação de recursos da cultura e uma expansão dos leitores de classe média urbana, que incluía o traçado de um generoso mapa de circulação do livro, que incluía o traçado de um generoso mapa de circulação do livro e que contemplava o círculo virtuoso livro-escola-cidadania e apostava nele. O ensaio, a cultura e o fazer dos nossos homens de letras correspondiam à exigência de representatividade social das representações intelectuais.

Mas houve, também, problemas e contradições em um modelo que partia do eixo hispano-americano e, embora se apresentasse como inclusivo, não alcançou a desejada abertura ao Brasil, ao Caribe, aos Estados Unidos, e tampouco conseguiu integrar a fundo aquelas regiões, zonas, experiências culturais e sociais da América, que se colocavam, por sua vez, 
como subalternas. ${ }^{3}$ Tampouco atendeu às experiências plurais do mundo extraocidental nem se deixou permear, no caso de Reyes ou Henríquez Ureña, pelas propostas das vanguardas. Quando Germán Arciniegas escreve "Nuestra América es un ensayo", em 1963, confirma esse modo de entender o ensaio como respaldado na coluna vertebral da história da América, conduzido por um setor que é o da inteligência americana, e apoiado pela ideia de cultura assim como pela visão do Mediterrâneo como o grande modelo antecessor. $\mathrm{O}$ diálogo com a história se dá em decorrência da recuperação dos vínculos culturais com o Ocidente, que tingem com sua própria tonalidade a confluência de raças, e fica excluído o olhar a outras épocas, tempos e processos culturais extraocidentais, ao passo que a voz própria da subjetividade do ensaísta se dilui no discurso cidadão que procura se fixar no espaço público.

Um dos descendentes mais jovens dessa família é El espejo enterrado, de Carlos Fuentes, publicado em 1992 pelo Fondo de Cultura Económica. Vejo nele um dos últimos expoentes dessa genealogia, na medida em que é um dos últimos interessados em oferecer uma visão integradora da cultura latino-americana, na qual o arcabouço histórico se mantém, embora neste caso se abra à necessidade de incluir a experiência espanhola e a experiência norte-americana - não a brasileira -. O ensaísta autoriza sua própria voz que é, ao mesmo tempo, uma interpretação da cultura americana e sua própria biografia intelectual. Por sua vez, essa visão, desse lado, vincula-se aos novos fenômenos, redes e circuitos editoriais que estavam se repensando com a Espanha.

Esse modelo, que se acreditou inclusivo, podia se assomar sempre ao abismo e ao risco de um substancialismo e um essencialismo (Rincón) que, finalmente, resultaram no apoio de um novo autoritarismo, por sua vez excludente e subalternizador. Nesse sentido, chama a atenção o lugar ocupado pelo Contrapunteo de Ortiz, que colocou a literatura e a antropologia em um novo diálogo.

González Echevarría (2001, p. 78) recupera também um precioso ensaio de Octavio Paz sobre essas questões, publicado na revista Vuelta, em 1977:

\footnotetext{
3 Assim, por exemplo, o termo "América Latina", empregado pela primeira vez de maneira propositiva pelo chileno Francisco Bilbao, surgiu ligado à prédica de um setor intelectual subalterno, preocupado em entender outros setores populacionais rurais e populares; entretanto, mais tarde, foi em boa medida deslocado por um modelo hispano-americanista que não conseguiu superar uma visão basicamente crioula e urbana, ligada aos projetos liberais. Para Francisco Bilbao, ver Rafael Mondragón (2013).
} 
É possível reduzir a diversidade das obras hispano-americanas a alguns poucos traços característicos [...] Por que se empenhar em definir o caráter da literatura latino-americana? [...] No seio de cada literatura há um diálogo contínuo feito de oposições, dúvidas e interrogações. A literatura hispano-americana não é um mero conjunto de obras, mas as relações entre essas obras. Cada uma delas é uma resposta, declarada ou tácita, a outra obra escrita por um predecessor, um contemporâneo ou um descendente imaginário. Nossa crítica deveria explorar essas relações...

Ainda nesse sentido, González Echevarría (2001, p. 78) comenta: “a questão não consiste apenas em deixar de procurar definições de caráter da literatura latino-americana, mas no porquê os escritores hispano-americanos têm buscado tanto defini-la".

Em um trabalho recente, Gustavo Guerrero (2014) faz uma interessante revisão de outros olhares que, investidos de maior malícia e perspectiva crítica, não deixam, de todo modo, de salvar a ideia de cultura latino-americana: Carlos Monsiváis e García Canclini (apud GUERRERO, 2014, p. 73), entre outros, para os quais é aconselhável, como diz este último, conseguir "intercalar o nome latino-americanos no diálogo global", como "a condição para que nossa identidade não seja lida entre aspas. Guerrero (p. 74) também observa de maneira sagaz que, em boa medida, foi a partir do imaginário de Macondo que se reconfigurou "uma certa interpretação da cultura latino-americana como totalidade unificada ao redor de um relato de nossa diferença, cujo fundamento é o realismo mágico”.

No caso de Monsiváis, Guerrero (2014, p. 72) acrescenta que o latino-americano não é "um substrato quase metafísico de uma identidade coletiva e essencial" que "expressaria nossa irredutível diferença cultural perante a modernidade", antes, essa ideia associa-nos a

[...] uma infinidade de problemas econômicos, políticos, sociais e ecológicos que se formulam hoje para além das nações. Nesse sentido, falar de uma cultura latino-americana significa referir-se menos a uma etiqueta do que a um fórum aberto no qual se resolvem e se gerem nossas semelhanças e diferenças não só perante o passado, mas também frente ao porvir (2014, p. 72).

\section{O GÊNERO SEM MARGENS}

Darei um salto no tempo para me referir à passagem do ensaio "em terra firme”, concebida com o afã generalizante e integrador de diferenças, ao arquipélago de particularidades ou ao gênero "sem margens". Para começar, o conceito de cultura como entidade monolítica capaz de se 
reconciliar com um projeto civilizatório ampliado, mas que elude questões de subalternidade ou cultura popular, foi colocado em dúvida pela obra de ensaístas como o grande crítico de arte paraguaio Ticio Escobar (2008, p. 12) que, além disso, está consciente de muitas das mudanças vividas na região:

\begin{abstract}
No Paraguai, como na maioria dos países latino-americanos, há déficit de Estado e de sociedade, e superávit de mercado, o que aproxima o risco de que, frente a uma contrapartida dispersa e débil, o poderoso complexo industrial da cultura exacerbe as desigualdades, esmague as diferenças e termine postergando as possibilidades alternativas de integração cultural e, portanto, de mobilidade e coesão. Apesar de que o próprio modelo tem caído em importantes contradições, é particularmente forte o contrapeso de novos fenômenos de mercado, importação, academicização etc. Não podemos negar a incidência de outros fatores, como o esvaziamento do lugar do interesse público, a desarticulação da vida social, cujos últimos vínculos já não podem resistir aos embates das novas formas de máfia e terrorismo social.
\end{abstract}

Outra questão que hoje se reformula é a da obediência a uma narrativa histórica única e a acervos da memória fixos, facilmente conserváveis e reproduzíveis. No par integrado pelas obras El olvido que seremos e Traiciones de la memoria, o colombiano Héctor Abad Faciolince traduz, por meio da narração da vida e do assassinato de seu pai, o esquecimento desse espaço comum de debate e de compreensão, a perda de um sentido de espaço público e, inclusive, de maneira trágica, o castigo mortal para quem defende esse espaço, a implosão do processo de modernização e urbanização que, de acordo com as instituições do Estado-nação, permitiram alcançar até certo ponto um equilíbrio de certo nível de inclusão para os setores médios. Em El olvido que seremos, um poema encontrado em um bolso converte-se em indício de uma trama de sociabilidade dilacerada que o próprio autor vai tentar recuperar em outra obra complementar à anterior, Traiciones de la memoria, em que o seguimento e a reconstrução narrativa de encontros, cartas, fotografias, evocações, citações, versões, permitem-nos recuperar um exercício de sociabilidade fundamental dada como "cumplicidade de sentido": a mediação do narrador coloca-se como requisito para aceder à voz de outros em perigo de apagamento. No "Prólogo" lemos:

Quando alguém sofre dessa forma tão peculiar da brutalidade que é a má memória, o passado tem uma consistência quase tão irreal quanto o futuro [...] nunca estou completamente seguro se estou rememorando ou inventando. Quando vivemos as coisas, nesse tempo "durante" que chamamos presente, com esse peso devastador que tem a realidade imediata, tudo parece trivial 
e consistente e duro como uma mesa ou uma cadeira; ao invés disso, quando passa o tempo [...] as coisas terminam sendo tão irreais como [...] um objeto que pode existir tão somente nas palavras (ABAD FACIOLINCE, 2010, pp. 11-12).

A dimensão ética e jurídica do ensaio, acentuada a partir das novas condições tecnológicas e suas implicações nos problemas de autoria e plágio, também aflora em muitos textos hoje. Assim, Leonardo Padura (2013), em “¿Se extinguirán los escritores?”, refere-se aos “problemas materiais e subjetivos que acompanham a mutação de novas tecnologias, em fenômenos que incidem fortemente na indústria cultural". Mais uma vez o problema de autoria de uma obra toca os problemas jurídicos: quem é o autor de um texto em tempos nos quais novos suportes modificam inclusive as condições de reprodutibilidade técnica que Benjamin chegou a conhecer? Diante da forte ofensiva de reprodução de ideias que a internet oferta e da crescente tendência a se apoderar das citações e das ideias dos outros, Padura se pergunta tanto por questões de autoria quanto pela responsabilidade social de todo escritor. Segundo o autor cubano, a retração do processo de profissionalização do escritor implica a retração de um tipo de especialista da palavra: quem se dedicará a falar do amor, da dor e da beleza agora? Mais uma vez, questões ligadas aos direitos do autor se enlaçam com problemas de responsabilidade e legitimidade do dizer.

O apagamento dos limites e a superposição ou, inclusive, a usurpação de funções entre distintas formas discursivas se manifesta em um crescente número de obras. Para isso contribuem novos fenômenos, como a hipertextualização, a fragmentação e a derivação de linhas de pensamento, a reciclagem de ideias, a pulverização de citações, que se incrementam com o uso do computador. "O que tens entre tuas mãos, querido leitor, é um mapa. Não há nomes próprios, mas links. Territórios de procura", diz Cristina Rivera Garza (2011), em "El escritor en Ciberia”, e acrescenta observações como esta:

A era da globalização teria que ser, inevitavelmente, a era da tradução. Escrever é traduzir [...] O livro que se faz hoje mesmo, em algum lugar da Tela Cujo Nome, é um livro escrito diretamente em tradução. Há alguém, sem dúvida, que vive em Outro Lado e, utilizando inclusive palavras de sua Própria Língua, escreve na verdade em Outroladês [...].

Também é muito interessante sua reflexão sobre as mudanças no sujeito e as subjetividades a partir da emergência do homo technologicus: 
Houve, alguma vez, um homo psychologicus. Tratava-se desse ser humano das sociedades industriais, que construiu muros grossos para separar o privado do público e proteger, assim, uma noção silenciosa e profunda, individual e estável, do eu [...]. Em seu lugar se configurou o homo technologicus: um ser pós-humano que habita os espaços físicos e virtuais das sociedades informáticas, para quem o eu não é nem segredo nem uma profundidade nem muito menos uma interioridade, mas, pelo contrário, uma forma de visibilidade. Conectado a digitalidades diversas, o homo technologicus escreve essa vida que só existe para que apareça inscrita em fragmentos de circulação constante (RIVERA GARZA, 2011, p. 5).

Em nossos dias, não só assistimos à crise de um modelo que procurava abrir, permear e expandir a possibilidade de uma prosa de terra firme apoiada em uma relação forte entre cultura, linguagem e literatura, mas também, e muito pelo contrário, ele foi ameaçado não só pelas suas próprias contradições, como pelos novos processos de retrações do Estado e avanço dos interesses particulares em um mundo em crescente complexificação e fragmentação, em que assistimos a processos que muitas vezes têm mais a ver com a Idade Média que com a modernidade avançada, como a crise do espaço urbano ou a crise do modelo educativo ou da indústria editorial. O espaço de um "nós" se retrai a uma área incerta e frágil ligada à coexistência diária, na qual se desconfia da relação entre o eu e os outros. A esses elementos eu acrescentaria a perda do diálogo entre diferentes atores em campo, entre autor e tradição, entre autor e leitor e, em geral, a contínua posposição de um diálogo com outras culturas e experiências. O esvaziamento do lugar de interesse público, a burocratização das zonas-chave para a decolagem da era do conhecimento, a desarticulação da vida social, cujos últimos vínculos já não podem resistir aos embates das novas formas de máfia e terrorismo, são um desafio para esse gênero, marcado pelo cronotopo do encontro e pela responsabilidade da palavra. Tudo isso acarreta um forte ressurgimento de certa ordem jurídica, uma reformulação do campo literário e sua relação com o mundo social, um regresso à precariedade do particular, um interesse crescente pela exploração da subjetividade e da experiência interior, uma tentação em alguns autores pelo trovar clus dos elegidos e, em outros, uma tentação de se aproximar dos novos circuitos que as literaturas pós-autônomas vão traçando (LUDMER, 2005, pp. 155-156).

As crises do conceito de América Latina, do conceito de literatura, da noção de interesse público, do papel dos intelectuais, da cultura do livro, assim como os novos fenômenos de circulação da palavra, também 
se desdobraram em novas soluções simbólicas. Muitos de nossos ensaístas se dedicam a pensar em novos cenários e realidades. O brasileiro Renato Ortiz (200o, p. 44) já formulava, há muitos anos, a pergunta pela existência de distintas "Américas Latinas".

$\mathrm{O}$ argentino Carlos Altamirano refere-se aos distintos elementos que realizam a mutação de nossa paisagem cultural: o advento da ordem midiática, a crise das filosofias da história nas quais os intelectuais fundaram o sentido de compromisso político, as mudanças da relação entre cultura e política, a fragmentação do conhecimento, a especialização: poderiam os intelectuais "reclamar um ponto de vista da totalidade" (ALTAMIRANO, 2013, p. 10), tal como acreditava Karl Mannheim, diante dessa multiplicação de saberes e linguagens?

Muitos de nossos maiores ensaístas dedicam-se a identificar e nomear os novos fenômenos que se apresentam. Assim, no que concerne a nossa discussão, Gustavo Guerrero (2009) refere-se, na já mencionada "Crítica del panorama”, à “falta de espaços de mediação”, e a "um espaço literário sobressaturado, segmentado, confuso", hoje atravessado, acrescento por minha parte, por megaestradas informáticas que interconectam, mas também, em muitos casos, desvirtuam a relação entre o local e o global, convertidos em versões do glocal e o googlobal.

A verdade é que os livros, diz Guerrero (2009), "circulam mal na América Latina", com forte dispersão geográfica e debilidade de distribuição em nível continental. A isso se somam processos de "leitura fragmentária, estética do particular, o díspar, o irredutível”, e a isso podemos acrescentar os novos processos de "subjetivização" da palavra. As "dificuldades para pensar um espaço literário único" derivam, como Guerrero aponta certeiramente, em mercados e consumo massivo, nichos culturais, produtos mais minoritários, paisagens segmentadas, arvorecências. Em suas palavras, também poderíamos falar em "dificuldades para pensar um espaço cultural único" como apoio para um imaginário do latino-americano, que derivou em múltiplas respostas ensaísticas. Guerrero (2009) também aponta:

Em todo o caso, o certo é que também será necessário que se renovem os hábitos de leitura e que alguns críticos, jornalistas e universitários acabem aceitando o desaparecimento definitivo do panorama, tal e qual concebido até alguns anos atrás: a saber, como o ilusório espelho de uma totalidade. No lugar daquelas visões supostamente totais - que, no fundo, e como vetores de metarrelatos, sempre foram parciais -, há de se acostumar agora às paisagens segmentadas que elaboram as comunidades de leitores nas 
redes ou às arborescências que resultam do modesto exercício de discernir fragmentariamente, entre um punhado de obras e autores, esses traços de um ar de família que variam de indivíduo a indivíduo e que nenhum consegue esgotar ou resumir. Provavelmente muitos veem nisso um projeto crítico escassamente ambicioso, mas, na verdade, talvez não o seja tanto. Pois ao colocar de relevo a coexistência de estilos, temas, escrituras, formas e gêneros distintos que não se neutralizam nem se excluem, talvez se esteja se abrindo o caminho para o labor dos filósofos que hoje veem na heterogeneidade da criação contemporânea um modelo pluralista para pensar a universalidade sem totalidade das sociedades por vir.

Todos esses fatores foram dando lugar a diversas resoluções simbólicas, que são respostas criativas à necessidade de propor novas perspectivas e ordens a um conjunto que se evidencia cada vez mais complexo e instável, no qual os fenômenos confluem, convivem, superpõem-se, sem necessariamente se integrar. Esse é o caso do livro de ensaios que leva o título Aires de familia, de Carlos Monsiváis (200o), que se vê obrigado a evocar a noção tão valiosa de Wittgenstein para falar da sociedade e da cultura da América Latina.

Em nossos dias contamos com releituras inovadoras e apaixonantes de todos esses fenômenos. É o caso do Atlas portátil de América Latina. Arte y ficciones errantes, de Graciela Speranza, publicado em 2012 por Anagrama, em Barcelona, em caráter de finalista do Prêmio de Ensaio convocado pelo mesmo selo editorial e difundido por meio desses circuitos de distribuição. Assim, conhecemos esse livro graças às novas modalidades de seleção, investimento, marketing, circulação e oferta em livrarias, decididos pelos grandes consórcios editoriais espanhóis. Ao mesmo tempo, a obra de Speranza articula-se com outro projeto on-line: a revista eletrônica Otra Parte, Revista de Letras y Artes. ${ }^{4}$ Contamos também com outro texto lúcido, Pasajes de Proteo. Residuos,

\footnotetext{
4 A apresentação da revista diz o seguinte: "Otra Parte é uma revista quadrimestral independente, dedicada à crítica e ao ensaio sobre literatura, artes plásticas, cinema, fotografia, música, teatro e aos chamados meios mistos, a todo pensamento com o qual esses campos confluam ou dialoguem, e à apresentação gráfica da obra de artistas contemporâneos. Enquanto boa parte da política se fecha em um pragmatismo obstinado e o pensamento teórico gira em torno de sua herança recente, a arte volta a ser a produção em que se fazem as perguntas mais certeiras, as mais impertinentes, e surgem configurações inusitadas. Os que fazemos Otra Parte acreditamos que a arte e a literatura atuais são fontes de reflexão sobre o significado do presente, a direção do que está por vir e as opções ao fatalismo, que as artes estão em contínuo estado de dar à luz, porque não as incomoda que o presente seja incerto e que nas formas artísticas se vislumbrem endereços da vida ainda inacessíveis a outras linguagens".
} 
límites y paisajes en el ensayo, la narrativa y el arte latinoamericanos, de Fernando Zalamea (2013), também laureado com um prêmio de ensaio e publicado no México pela editora Siglo XXI. Chama atenção que, em ambos os casos, a pergunta pela América Latina se traduz em uma pregunta pela arte e uma resposta apoiada na dimensão imaginária; não obstante, também supõe o exercício de elaboração de uma nova cartografia imaginária da América, alternativa ao velho mapa apoiado em terra firme. Isso lembra uma antiga observação sobre o ensaio, como aquele gênero que se dedica a salvar, por meio de operações estéticas, contradições e pontos de estrangulamento que não podem ser superados a partir de outras ordens do saber.

Zalamea (2013) procura salvar a tradição crítica e criativa da América Latina com base em um novo lugar, colocando em diálogo a literatura, as artes plásticas, a música e as leituras provenientes da linha do ensaio em terra firme, posicionando-se criticamente tanto a respeito dos estudos culturais e dos neologismos por eles formulados, quanto a respeito dos reducionismos identitários e temporais que se aplicaram à experiência americana, para propor que, de todo modo, é possível rastrear processos de dialogização e diagonalização que permitam entender o contraste fantástico entre "implosão social e explosão criativa" e recuperar uma "história cultural" da América Latina.

Por outro lado, o ensaio de Speranza busca um ordenamento móvel, dinâmico, cujas peças podem se recombinar repetidamente, para dar conta da produção artística e literária da América Latina, assim como dos próprios pressupostos identitários do latino-americano. A deflagração do ensaio é aleatória, o ritmo está dado por um efeito de montagem de fragmentos, associação de ideias e experiências, montagem e desmontagem de mostras e demonstrações, que constituem um novo caminho com respeito ao modelo com que abrimos estas páginas, isto é, um ensaio que pisa na terra firme e se apoia nas próprias noções de cultura e devir histórico concebidas como integrais e integradoras.

O gesto que desencadeia o ensaio é, aqui, a própria experiência de estranheza de uma crítica de arte argentina diante de uma exposição no Reina Sofía, onde constata a ausência de artistas latino-americanos. A autora se pergunta:

O que esperava então? Que tivesse forçado a seleção para dar lugar à arte "periférica", obedecendo à ética multiculturalista do "reconhecimento" do Outro? Na partilha que a mente ilustrada e suas taxonomias fizeram durante 
séculos, à arte e às ficções da América Latina correspondeu o lugar da política enervada, a maravilha naturalizada e o disparate atroz, variedades mais ou menos solapadas do exotismo colonial. Hoje, por outrolado, o multiculturalismo se converteu em lógica cultural do capitalismo multinacional (o capital global já não opera com os padrões conhecidos de homogeneização cultural, mas com mecanismos mais complexos que exaltam a diversidade para expandir o mercado) e é preferível a omissão franca à condescendência forçada [...] Porque se é certo que nas últimas décadas o Sul entrou por fim na cena da arte contemporânea, a ampliação do mapa global parece dever mais à voracidade do mercado que às cruzadas teóricas democratizadoras do pós-colonialismo, o multiculturalismo e os estudos subalternos. A arte e a literatura latino-americanas, salvo contadas exceções, não alcançaram ainda uma presença real no atlas da arte do mundo que prescinda do rótulo identitário (SPERANZA, 2012, p. 12).

A reposta ao próprio desafio é a possibilidade de apelar ao atlas, de se apropriar do atlas como tema de reflexão, como modelo de construção e como modelo para estabelecer um novo tipo de diálogo com os leitores-espectadores. É como resposta a essa falta que Speranza construirá um ensaio que é, por sua vez, um atlas de permanente reenvio e combinações infinitas. Um admirável atlas que estabelece, precisamente, cruzamentos e ares de família: "atlas, arquivos líquidos, mapas conjunturais, que oscilam entre a tentação de se entregar a um fluxo descontínuo de imagens e textos que nos intervalos revelam a sobrevivência de outros textos e outras imagens" (SPERANZA, 2012, p. 11).

"Atlas, arquivos líquidos, mapas conjunturais" apontam para um novo ordenamento simbólico de um mapa mais próximo à montagem de peças, ao encontro de fragmentos, à possibilidade de enlaces de sentido que, por sua vez, replicam novos percursos, poéticas da relação "que deixam ver a variedade inesgotável do diverso" (SPERANZA, 2012, p. 194) e abrem a possibilidade de novas ordens de limiar e de fronteira, que superam paisagens pós-apocalípticas.

Em contraste com a solução simbólica integradora dada pelo conceito conteudista e ideal de cultura, Graciela Speranza propõe um olhar mais próximo a um enfoque relacional centrado nas práticas e, assim, realiza sua busca por meio do cronotopo do atlas, de novas formas de encontro e diversas formas de confluência, aleatórias e, ao mesmo tempo, necessárias, entre experiências e propostas estéticas. As reflexões que Speranza dedica à montagem e ao atlas servem como a "caixa preta" de sua própria proposta organizadora. Em um permanente diálogo e contraponto de imagens e textos, o fio condutor é a performance de sua própria reflexão, e o diálogo está representado no estilo indireto livre, 
que autoriza sua própria palavra. A articulação histórica, a articulação no tempo, vê-se deslocada pelo predomínio do espacial; a história é, então, uma operação de enlace sem ponto fixo, que se faz a partir do interior dos fenômenos colocados em relação.

Esse grande ensaio dedicado a dialogar com as imagens e objetos, admite essa nova dimensão do mundo, deflagrada pelo objeto encontrado de Duchamp, ao passo que sugere uma nova chave para a interpretação do próprio ensaio. As condições de diálogo entre ensaísta e leitor se instauram a partir de um atlas, que mediatiza a relação entre as instâncias, colocado como coisa em si que objetifica uma relação e inventa também um espaço do entre-dois.

\section{O ARQUIPÉLAGO RELACIONAL}

No Caribe, Édouard Glissant (1990) tinha colocado a necessidade de formular uma "poética da relação". Considero que a noção de "relación" é fundamental para entender a tarefa contemporânea do ensaio, que é necessariamente um permanente esforço de salvação do particular e do diferente na vinculação entre o homem e o mundo, o sabido e o por conhecer, o autor e o leitor, assim como, também, um exercício de mediação baseado na curiosidade intelectual e atento à relação aberta entre mundos.

Da perspectiva desse grande pensador martiniquense, é necessário postular, em contraste com o modelo mediterrâneo, o modelo do mar do Caribe, o modelo do arquipélago relacional. Desse modo, longe de afirmar um destino manifesto de origem exclusiva e orientação uniforme para o ensaio, prefiro falar das distintas formas de manifestação de um sentido, isto é, pensar as identidades por meio de formas relacionais e diversas que, ao invés de buscar fechamentos e sínteses, não façam senão mostrar a possibilidade de expansão de nossa família literária como uma permanente forma de diferenciação aberta.

Assim, o "mapa do ensaio" se mostra hoje como um arquipélago complexo, permanentemente reconfigurado em função de uma inter-relacionalidade aberta e dinâmica. O lugar de enunciação recebe hoje particular atenção, assim como o próprio ato de escrita possui particular importância.

Para terminar, direi que algumas das zonas mais chamativas desse arquipélago são, por exemplo, as novas aproximações ao mundo 
apoiadas em novas operações de cruzamento entre o âmbito expositivo e o narrativo, o ficcional e o não ficcional ou, inclusive, os ensaios em que o autor performa e ao mesmo tempo problematiza seu papel de mediador entre formas e discursos em perspectiva glocal. Hoje, o ensaio tematiza também a nova relação com o pacto autobiográfico e o pacto representativo, que incluem tanto um forte giro subjetivo e autobiográfico como uma reformulação dos efeitos de verdade e realidade. Uma das formas mais pronunciadas de engaste do ensaio em outros gêneros, aos quais assistimos atualmente, é sua relação com a crônica, mas também com a crítica de arte e a reflexão estética.

Há também algumas mudanças na estratégia discursiva: da parte pelo todo, baseada na representatividade, passamos ao todo só apreensível pela organização possível das partes; a avaliação cede seu lugar à descrição, à nomeação e à sugestão de sentidos. Novas constelações de leitura também se apresentam a partir de novas formas de relação entre as obras antes consideradas centrais e as obras outrora consideradas satélites.

Em suma: muitos são os exemplos que nos mostram como, por caminhos novos que já não passam pela velha ligação entre literatura e cultura, procura-se encontrar novas versões móveis, abertas, relacionais, multidirecionais, do latino-americano.

Do mapa cultural que garantia e era garantido pela narrativa da história, passamos à cultura mapeada, concebida como combinatória infinita, e só passível de ser organizada por meio de atlas, cartografias ou arquivos móveis.

Assistimos ao fechamento de um determinado modelo de ensaio centrado em uma proposta de síntese e articulação entre cultura-história-língua-literatura, para nos abrirmos às concepções abertas, relacionais, em que ingressam novos temas e problemas, assim como uma nova concepção de linguagem, a escritura, a(s) cultura(s), os cruzamentos genéricos. Em um século poderemos submeter à crítica esta chamativa "preeminência do conceito de cultura, seu lugar como fundamento de todo estudo sobre literatura latino-americana" (GONZÁLEZ ECHEVARRÍA, 2001, p. 75), até convertê-la em objeto de análise, e não de acordo implícito? Há muita coisa por fazer no estudo do ensaio, e este deve ser cada vez mais abarcador e inclusivo, visto que não se trata de destruir acriticamente as narrativas instituidoras e os arquivos da memória em que nos sustentamos, mas de submetê-las à revisão crítica à luz dos novos tempos, das novas discussões e dos novos 
desafios. Recordemos, mais uma vez que, como ato de sentido, o ensaio se dá em plena relação com o mundo.

\author{
Tradução: Chayenne Orru Mubarack \\ Revisão da tradução: Ana Cecilia Olmos
}

\title{
REFERÊNCIAS
}

ABAD FALCIOLINCE, Héctor. El olvido que seremos. Barcelona: Seix Barral, 2007.

ABAD FALCIOLINCE, Héctor. Traiciones de la memoria. Madrid: Alfaguara, 2010.

ALTAMIRANO, Carlos. Intelectuales. Notas de investigación sobre una tribu inquieta. Buenos Aires: Siglo XXI Editores, 2013.

ANGENOT, Marc. La parole pamphlétaire. Typologie des discours modernes. Paris: Payot, 1982.

ARCINIEGAS, Germán. Nuestra América es un ensayo. Cuadernos, n. 73, 1963, pp. 9-16.

BAJTIN, Mijail. Las formas del tiempo y del cronotopo en la novela. In: Teoría y estética de la novela; trabajos de investigación. Trad. Helena Kriúkova y Vicente Cazcarra. Madrid: Taurus, 1989[1975].

CASTORIADIS, Cornelius. La institución imaginaria de la sociedad. Trad. Antoni Vicens y Marco-Aurelio Galmarini. Barcelona: Tusquets Editores, 2013[1975].

DELCROIX, Maurice; HALLYN, Fernand (orgs.). Méthodes du text: introduction aux études littéraires. Lovaina: Duculot, 1995.

DOSSE, François. La marcha de las ideas. Historia de los intelectuales, historia intelectual. Trad. Rafael F. Tomás. Valencia: PUV, 2006[1993].

ESCOBAR, Ticio. El mito del arte y el mito del pueblo. Cuestiones sobre arte popular. Santiago de Chile: Ediciones Metales Pesados, 2008.

FUENTES, Carlos. El espejo enterrado. Cidade do México: FCE, 1992.

GEERTZ, Clifford. La interpretación de las culturas. Barcelona: Editorial Gedisa, 1988[1973].

GLISSANT, Édouard. Poétique de la relation. Paris: Gallimard, 1990.

GONZÁLEZ ECHEVARRÍA, Roberto. La voz de los maestros. Escritura y autoridad en la literatura latinoamericana moderna. Madrid: Verbum, 2001.

GUERRERO, Gustavo. Crítica del panorama. Letras Libres, n. 93, 2009, pp. 24-33. 
Remate de Males, Campinas-SP, v. 37, n. 2, p. 523-546, jul./dez. 2017 - 545

GUERRERO, Gustavo. Modos, rutas y derivas del ensayo contemporáneo. De la tierra firme al mar sin orillas. Revista de la Universidad, n. 126, 2014, pp. 63-75.

HENRÍQUEZ UREÑA, Pedro. Seis ensayos en busca de nuestra expresión. Buenos Aires: Babel, 1928.

LUDMER, Josefina. Aquí América Latina. Buenos Aires: Eterna Cadencia, 2005.

MAINGUENEAU, Dominique. Pragmatique pour les discours littéraire. Paris: Nathan Université, 2001.

MARIÁTEGUI, José Carlos. Temas de nuestra América. Lima: Biblioteca Amauta, 1960.

MARTÍ, José. Nuestra América. In: Obras completas, tomo VI. Havana: Editora Nacional de Cuba, 1962[1891].

MONDRAGÓN, Rafael. Anticolonialismo y socialismo de las periferias. Francisco Bilbao y la fundación de la Tribune des peuples. Latinoamérica. Revista de Estudios Latinoamericanos, n. 56, 2013, pp. 105-139.

MONSIVÁIS, Carlos. Aires de familia. Cultura e sociedad en América Latina. Barcelona: Anagrama, 200o.

ORTIZ, Renato. América Latina. De la modernidad incompleta a la modernidad-mundo. Nueva sociedad, n. 166, 2000, pp. 44-61.

PADURA, Leonardo. ¿Se extinguirán los escritores? El País, 27/7/2013.

PICÓN-SALAS, Mariano. De la conquista a la independencia: tres siglos de historia cultural hispanoamericana. Caracas: Monte Ávila, 1944.

RIVERA GARZA, Cristina. El escritor en Ciberia. El País, 19/11/2011.

SAER, Juan José. El río sin orillas. Buenos Aires: Seix Barral, 1991.

SAID, Edward. The World, the Text and the Critic. Cambridge: Harvard University Press, 1983.

SAPIRO, Gisèle. La guerre des écrivains, 1940-1953. Paris: Fayard, 1999.

SAPIRO, Gisèle. La responsabilité de l'écrivain. Paris: Seuil, 2011.

SCHAEFFER, Jean-Marie. Pequeña ecología de los estudios literarios. Cidade do México: FCE, 2013.

SEGOVIA, Tomás. Trilla de asuntos. Ensayos 11. Cidade do México: UAM, 1990.

SPERANZA, Graciela. Atlas portátil de América Latina. Arte y ficciones errantes. Barcelona: Anagrama, 2012. 
O ensaio em diálogo. Da terra firme ao arquipélago relacional - 546

VITIER, Medardo. El ensayo americano. Cidade do México: FCE, 1945.

WEINBERG, Liliana (org.). Estrategias del pensar. Ensayo y prosa de ideas en América Latina Siglo XX. Tomos 1 y 11. Cidade do México: CIALC-UNAM, 2010.

WILLIAMS, Raymond. Marxismo y literatura. Barcelona: Península, 1980.

ZAID, Gabriel. Paradojas de la cultura. Reforma, 17/11/2013.

ZALAMEA, Fernando. Pasajes de Proteo. Residuos, límites y paisajes en el ensayo, la narrativa y el arte latinoamericanos. Cidade do México: Siglo XXI, 2013. 